\title{
Prevalence of Asymptomatic Mycobacterium tuberculosis Infection in Charcoal Producers: A Cross-Sectional Study in Kaase, Ghana
}

\author{
Benjamin Kwame Senya, Nketiah Bernard Anim, Bright Segu Kobena Domson, \\ and Patrick Adu \\ Department of Medical Laboratory Science, College of Health and Allied Health Sciences, University of Cape Coast, Ghana \\ Correspondence should be addressed to Patrick Adu; patrick.adu@ucc.edu.gh
}

Received 14 May 2018; Accepted 26 July 2018; Published 2 August 2018

Academic Editor: Giovanna Franciosa

Copyright (C) 2018 Benjamin Kwame Senya et al. This is an open access article distributed under the Creative Commons Attribution License, which permits unrestricted use, distribution, and reproduction in any medium, provided the original work is properly cited.

\begin{abstract}
Background. Charcoal production is a significant economic activity in Ghana. However, there is scarcity of data on the risk of acquiring Mycobacterium tuberculosis infection among charcoal producers in Ghana, even though persistent smoke exposure is a known predisposition factor. Methods. This cross-sectional study recruited 40 charcoal producers: 6 males and 34 females. Two sets of early morning sputum samples were collected from each participant and examined for the presence of acid-fast bacilli (AFB) using fluorescent microscopy. Structured questionnaires were used to retrieve demographic data from each participant. Data were analyzed using SPSS version 21 and presented as frequencies and proportions. Categorical variables were compared using Chi-square test. Significant difference was identified as $p<0.05$ at $95 \%$ confidence interval. Results. Overall, 2/40 (5\%) of the participants demonstrated AFB in their sputum. All participants with AFB positive sputum were females and had 6-10 years of experience in charcoal production. Whereas coughing was the most self-reported symptom by the charcoal producers, none complained of blood in sputum. Also, only 9/40 (22.5\%) had knowledge about the Mycobacterium tuberculosis-infection risk associated with charcoal production. Moreover, 62.5\% (25/40) of participants had no formal education. Conclusion. Education on personal protection equipment must be a public health priority in these charcoal producers in Ghana as sawdust and smoke exposure may predispose charcoal producers to acquisition of tuberculosis.
\end{abstract}

\section{Introduction}

Tuberculosis $(\mathrm{TB})$ is a global public health problem caused by Mycobacterium tuberculosis. One-third of the world's population is thought to be infected with TB [1]. According to Patra et al. [2], about 8.6 million people developed active TB with at least 1.3 million mortalities mainly in resource-limited countries. In 2014, there were 9.6 million cases of active TB which resulted in 1.5 million deaths with more than $95 \%$ of the deaths occurring in developing countries [1]. Also, the number of cases of TB per 100,000 people was highest in sub-Saharan Africa in 2007 [3]. TB is among the commonest communicable diseases in Ghana with a reportedly over 250,000 more Ghanaians acquiring M. tuberculosis infection each year [4].

TB is transmitted by droplet inhalation produced by coughing, singing, and sneezing of an infected person.
Certain lifestyle choices and occupations are known to predispose individuals to risk of contracting the bacterium and subsequently developing active infection. Previous findings have shown that exposure to particulate matter and smoke from carbonizing wood is a risk factor for developing $\mathrm{TB}$ in case-control studies conducted in India [5], Nepal [6], and Metropolitan Mexico City [7]. Another study also showed that exposure to wood smoke is associated with the development of TB in children aged $\leq 17$ due to the immaturity of their respiratory and immune system [8]. Also, analysis of data from 200,000 Indian adults found an association between self-reported tuberculosis and exposure to wood smoke [9].

The global production of wood charcoal was estimated at 47 million metric tonnes in 2009 and increased by $9 \%$ since 2004 with Africa accounting for 63\% of global production. Ghana is rated as the 9th producer of wood charcoal, producing $3 \%$ of the entire world wood charcoal [10]. Even 
TABLE 1: Age group of participants according to gender of participants.

\begin{tabular}{lccr}
\hline Characteristic & Male (\%) & Female (\%) & Total (\%) \\
\hline Age Group & & & $3(7.5)$ \\
$15-24$ & $2(5.0)$ & $7(17.5)$ & $8(20.0)$ \\
$25-34$ & $1(2.5)$ & $9(22.5)$ & $11(27.5)$ \\
$35-44$ & $2(5.0)$ & $7(17.5)$ & $8(20.0)$ \\
$45-54$ & $1(2.5)$ & $3(7.5)$ & $3(7.5)$ \\
$55-64$ & $0(0.0)$ & $5(12.5)$ & $5(12.5)$ \\
$\geq 65$ & $0(0.0)$ & & \\
\hline
\end{tabular}

though charcoal production is a significant occupation in Ghana, studies assessing the incidence of asymptomatic TB infection among the charcoal producers are nonexistent. This study thus sought to provide such empirical data.

\section{Materials and Methods}

2.1. Study Design/Population. This was a cross-sectional study based on convenience sampling that recruited charcoal production workers with a minimum of one-year work experience and at least 15 years old at Kaase, a suburb of Kumasi, the regional capital of the Ashanti Region, Ghana. A total of 40 participants (6 males and 34 females) who gave informed consent were recruited.

2.2. Data Collection. Two (2) sets of morning sputum specimens (3-5 ml each) at 30 minutes intervals were collected from each participant for the study since sputum is best collected in the morning soon after the patient wakes up and before any antiseptic mouth-wash use.

2.3. Ethical Consideration. The study had approval from the University of Cape Coast Institutional Review Board (UCCIRB/CHAS/2016/47) and the Kumasi South Hospital authorities. A written consent was sought from interested participants after the procedures were clearly explained to them. Results and records were strictly kept confidential.

2.4. Sputum AFB. Sputum specimen from each participant was identified with a unique numbering system followed by A or B indicating soon after the patient wakes up and before any antiseptic mouth-wash use, respectively. Florescence microscopy was done after fluorochrome staining following standard protocols and bacteria found graded according to the International Union against Tuberculosis and Lung Disease (IUATLD)/WHO for reporting the sputum smear microscopy results [11].

2.5. Data Analysis. The data obtained was entered and stored in Microsoft Excel and analyzed using Statistical Package for Social Sciences (SPSS) software version 21.0 (IBM Inc., USA). Summary descriptive statistics were used to describe the study population and reported using frequency table, bar chart, and cross-tabulation. Pearson's Chi-square model $\left(\chi^{2}\right)$ was used where appropriate to compare categorical variables
TABLE 2: Knowledge of TB-infection risk associated with charcoal production.

\begin{tabular}{lcc}
\hline & \multicolumn{2}{c}{ TB Knowledge } \\
& Yes & No \\
\hline Gender & 2 & \\
Male & 7 & 27 \\
Female & & \\
Age Group & 1 & 4 \\
15-24 & 1 & 5 \\
$25-34$ & 3 & 9 \\
$35-44$ & 2 & 7 \\
$45-54$ & 1 & 2 \\
$55-64$ & 1 & 4 \\
$\geq 65$ & 1 & \\
Educational Level & & \\
Primary & & 4 \\
JHS & 3 & 5 \\
SHS & 0 & 2 \\
None & 1 & 20 \\
\hline
\end{tabular}

between groups. Significant differences were identified as $p$ value $<0.05$ at $95 \%$ confidence interval.

\section{Results}

The demographic characteristics of the participants are shown in Table 1. Among these, $15.0 \%$ were males and $85.0 \%$ were females. Majority of the males were within the age groups 15 to 24 years and 35 to 44 years whereas most of the females were within the age group 35 to 44 years.

The knowledge of the participants about TB is shown in Table 2. Whereas $2 / 6(33.3 \%)$ of males had some knowledge about TB, only $7 / 34$ (20.6\%) females had knowledge about TB. Overall, only $22.5 \%(9 / 40)$ of the participants had knowledge about TB. Also, whereas most [3/8 (37.5\%)] of the participants who had knowledge about TB were within the age group 25-34 years, only $12.5 \%$ (1/8) of participants within the age group of 45-54 years had knowledge about TB. Additionally, $62.5 \%$ (25/40) of the participants had had no formal education. Whereas $20 \%$ of participants with no formal education had some knowledge on the TB-risk 
TABLE 3: Grading of AFB in smears using fluorescent microscopy.

\begin{tabular}{lcc}
\hline Grade of AFB & $\begin{array}{c}\text { Number of Participants } \\
(\mathbf{N = 4 0 )}\end{array}$ & $\begin{array}{c}\text { Percentage } \\
(\%)\end{array}$ \\
\hline Negative & 38 & 95.0 \\
Scanty & 0 & 0.0 \\
$\mathbf{1 +}$ & 1 & 2.5 \\
$\mathbf{2 +}$ & 1 & 2.5 \\
$\mathbf{3 +}$ & 0 & 0.0 \\
\hline
\end{tabular}

TABLE 4: Prevalence of TB among participants based on gender and number of years of charcoal production.

\begin{tabular}{lcc}
\hline & $\begin{array}{c}\text { Positive } \\
\text { N (\%) }\end{array}$ & $\begin{array}{c}\text { Negative } \\
\text { N (\%) }\end{array}$ \\
\hline $\begin{array}{lcc}\text { Gender } \\
\text { Male }\end{array}$ & $6(15.0)$ \\
Female & $0(0.0)$ & $32(80.0)$ \\
Years of work & $2(5.0)$ & \\
$1-5$ & & $15(37.5)$ \\
$6-10$ & $0(0.0)$ & $19(47.5)$ \\
$>10$ & $2(5.0)$ & $4(10.0)$ \\
\hline
\end{tabular}

associated with charcoal production, none of participants with junior high education had any such knowledge.

Figure 1 presents self-reported prevalence of respiratory symptoms among the 40 participants. The most prevalent self-reported respiratory symptoms in the participants were cough (60.0\%) and expectoration (52.5\%), with none reporting of blood-stained sputum $(0.0 \%)$.

Table 3 presents the grading of AFB in sputum smear specimen as evaluated by fluorescent microscopy. Overall, $5.0 \%(2 / 40)$ of the participants tested positive to AFB; the grading was $>$ scanty but less than $3+$.

All the participants with positive AFB sputum smear were females (Table 4). Additionally, all female participants with positive AFB sputum smear had 6-10 years of experience with charcoal production.

\section{Discussion}

Studies have shown that combustion of wood releases large particulate matter such as carbon monoxide, nitrogen oxide, formaldehyde, and polyaromatic hydrocarbons which can deposit deep into the alveoli and can cause considerable damage to the respiratory system predisposing those exposed to such smoke to TB infection [12,13]. Although charcoal production workers abound in Ghana, there has not been any systematic study to address the long-term health implication of this vocation. Within the limits of the fluorescent microscopy technique, our study found 5\% prevalence of asymptomatic TB infection in charcoal producers in the Kaase community in Kumasi.

Our reported 5\% prevalence of asymptomatic Mycobacterium tuberculosis infection is higher than the $1 \%$ prevalence reported in a similar cross-sectional study in India

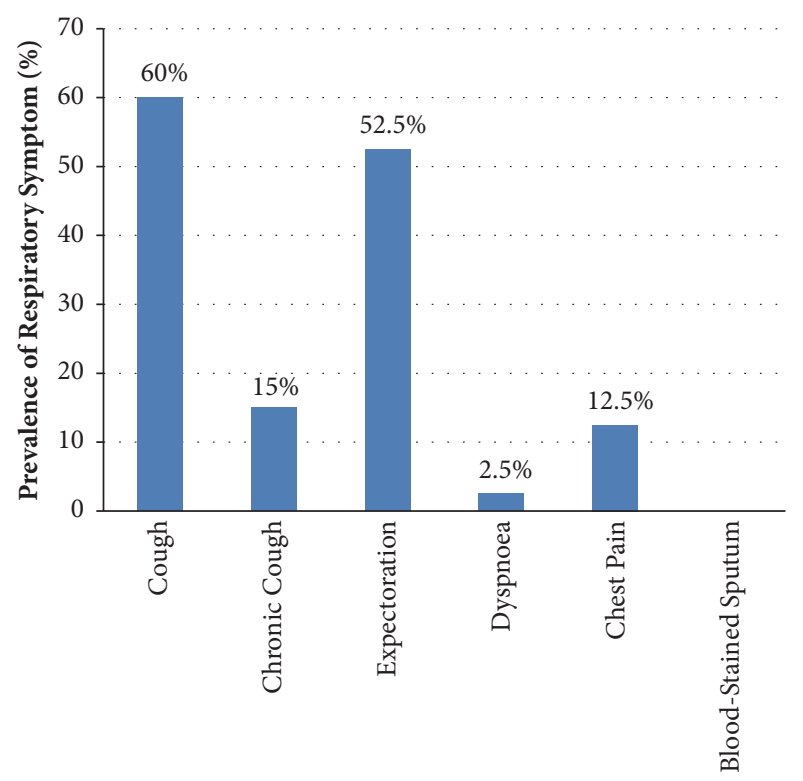

Respiratory Symptom

FIGURE 1: Self-reported prevalence of respiratory symptoms among participants. Chronic cough refers to any persistent cough lasting more than four weeks.

[14]. Our study is in agreement with previous reports that found wood smoke exposure as an important risk factor for the development of TB $[2,5-8,15]$. Interestingly, all the participants with positive AFB smear in the present study were females. This is not surprising because unlike the male participants whose job were only to pack the wood, the females, in addition to packing the wood, were also responsible for covering the pile with sawdust as well as controlling the carbonization process. Therefore, the females in our study population were exposed to larger quantities of smoke particles and sawdust, thus making them prone to TB infection. This notwithstanding, the male participants were considerably fewer than the females in the present study and this could have also skewed the finding of only females being infected with the bacterium. All the $2(5 \%)$ infected were workers who had been in the business for about 6-10 years.

The most prevalent self-reported respiratory symptom in this study was cough (60.0\%) followed by expectoration (52.5\%) with none of the participants reporting blood in their sputum. Saw dust used to cover the packed wood could have caused the inhalation of sawdust in addition to smoke particles which may irritate the respiratory system triggering the cough and expectoration reported by the participants. This is in agreement with a previous study in Brazil that reported cough as the most common lower respiratory tract symptom among charcoal production workers [16]. However, whereas some participants in the study in Brazil smoked, none of the participants in the present study smoked. It is important to note that none of the participants in the present study used personal protection equipment (PPE) when undertaking their charcoal production. This might have increased the exposure to smoke and particulate matter in the participants in the present study. 
The limitations of the present study include the small sample size used as well as the fluorescent microscopy technique employed. Whereas a larger sample size would have increased the statistical power, we anticipate that polymerase chain reaction-based technique such as GeneXpert could have estimated a higher prevalence considering its higher sensitivity.

\section{Conclusion}

Education on personal protection equipment must be a public health priority in these charcoal producers in Ghana as sawdust and smoke exposure may predispose charcoal producers to acquisition of tuberculosis.

\section{Data Availability}

The data used to support the findings of this study are available from the corresponding author upon request.

\section{Disclosure}

The research was cofounded by the authors.

\section{Conflicts of Interest}

The authors declare no conflicts of interest.

\section{Authors' Contributions}

Benjamin Kwame Senya, Nketiah Bernard Anim, and Bright Segu Kobena Domson were involved in participant recruitment, participant instruction on proper sample taking, experimental assays, and literature search. Bright Segu Kobena Domson and Benjamin Kwame Senya analyzed the manuscript; Bright Segu Kobena Domson drafted the manuscript. Patrick Adu conceived the idea and designed the research, supervised the project, interpreted the data, and revised the manuscript. All authors read and approved the final manuscript.

\section{Acknowledgments}

The authors are grateful to the laboratory unit of the Kumasi South Hospital for their assistance during the course of the study. They are also indebted to the charcoal production workers who agreed to be part of the study.

\section{References}

[1] World Health Organization, "Tuberculosis Fact sheet $\mathrm{N}$ 104. 2015," 2015, http://www.who.int/mediacentre/factsheets/ fs104/en.

[2] J. Patra, M. Bhatia, W. Suraweera et al., "Exposure to SecondHand Smoke and the Risk of Tuberculosis in Children and Adults: A Systematic Review and Meta-Analysis of 18 Observational Studies," PLoS Medicine, vol. 12, no. 6, p. e1001835, 2015.
[3] World Health Organization, Global tuberculosis control: epidemiology, strategy, financing: WHO report 2009, 2009.

[4] R. Q. Duho, "Ghana's TB burden higher thab estimated2013 Survey," 2013, https://www.graphic.com.gh/news/health/ ghana-s-tb-burden-higher-than-estimated-2013-survey.html.

[5] C. Kolappan and R. Subramani, "Association between biomass fuel and pulmonary tuberculosis: A nested case-control study," Thorax, vol. 64, no. 8, pp. 705-708, 2009.

[6] A. K. Pokhrel, M. N. Bates, S. C. Verma, H. S. Joshi, C. T Sreeramareddy, and K. R. Smith, "Tuberculosis and indoor biomass and kerosene use in Nepal: a case-control study," Environmental Health Perspectives, vol. 118, no. 4, article 558, 2010.

[7] R. Perez-Padilla, C Pérez-Guzmán, R Báez-Saldaña, and A. Torres-Cruz, "Cooking with biomass stoves and tuberculosis: a case control study," The International Journal of Tuberculosis and Lung Disease, vol. 5, no. 5, pp. 441-447, 2001.

[8] C. Gracia-Sancho, R. Fernandez-Plata, D. Martinez-Briseno et al., "Exposure to wood smoke and tuberculosis in children," Neumología y Cirugía de Tórax, vol. 72, pp. 281-286, 2013.

[9] V. K. Mishra, R. D. Retherford, and K. R. Smith, "Biomass cooking fuels and prevalence of tuberculosis in India," International Journal of Infectious Diseases, vol. 3, no. 3, pp. 119-129, 1999.

[10] B. Steierer, Highlights on wood charcoal: 2004-2009, Wood Energy, FAOSTAT-ForesSTAT, FAO Forestry Department, Rome, 2011.

[11] D. Lung, "Tuberculosis bacteriology-priorities and indications in high prevalence countries: position of the technical staff of the Tuberculosis Division of the International Union Against Tuberculosis and Lung Disease," The International Journal of Tuberculosis and Lung Disease, vol. 9, no. 4, p. 355, 2005.

[12] B. C. Boman, A. B. Forsberg, and B. G. J Lrvholm, "Adverse health effects from ambient air pollution in relation to residential wood combustion in modern society," Scandinavian Journal of Work, Environment \& Health, pp. 251-260, 2003.

[13] N. Bruce, R. Perez-Padilla, and R. Albalak, "Indoor air pollution in developing countries: a major environmental and public health challenge," Bulletin of the World Health Organization, vol. 78, no. 9, pp. 1078-1092, 2000.

[14] V. K. Mishra, R. D. Retherford, and K. R. Smith, "Effects of cooking smoke on prevalence of tuberculosis in India," 1997.

[15] M. Gegia, M. J. Magee, R. R. Kempker et al., "Tobacco smoking and tuberculosis treatment outcomes: a prospective cohort study in Georgia," Bulletin of the World Health Organization, vol. 93, no. 6, pp. 390-399, 2015.

[16] R. M. D. Souza, F. M. Andrade, A. B. Moura, and P. J. Teixeira, "Respiratory symptoms in charcoal production workers in the cities of Lindolfo Collor, Ivoti and Presidente Lucena, Brazil," Jornal Brasileiro De Pneumologia, vol. 36, no. 2, pp. 210-217, 2010. 


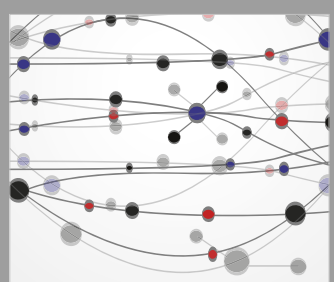

The Scientific World Journal
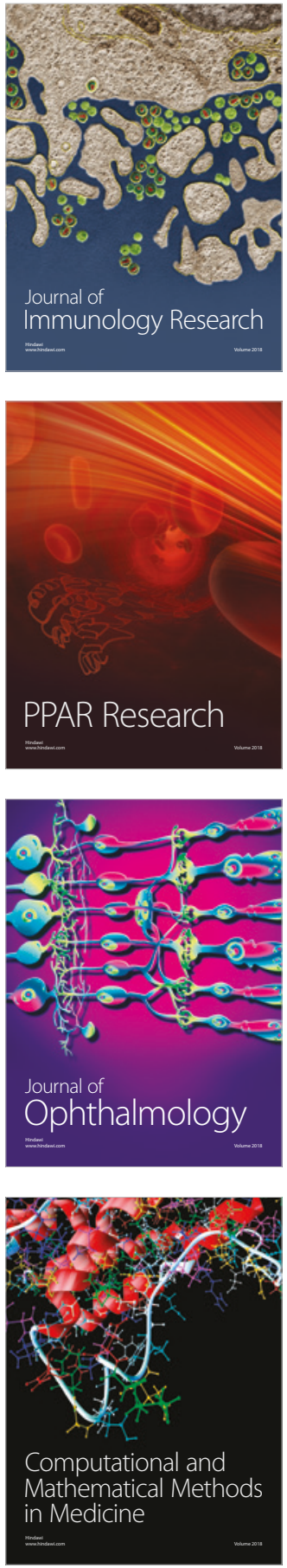

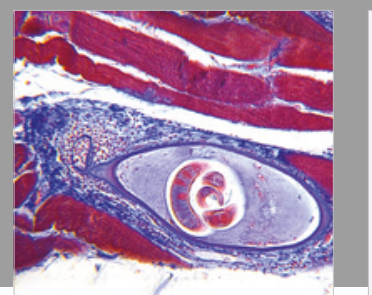

Gastroenterology Research and Practice

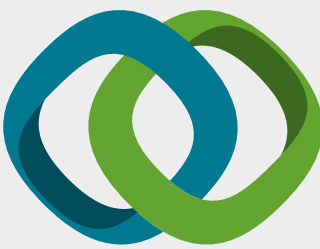

\section{Hindawi}

Submit your manuscripts at

www.hindawi.com
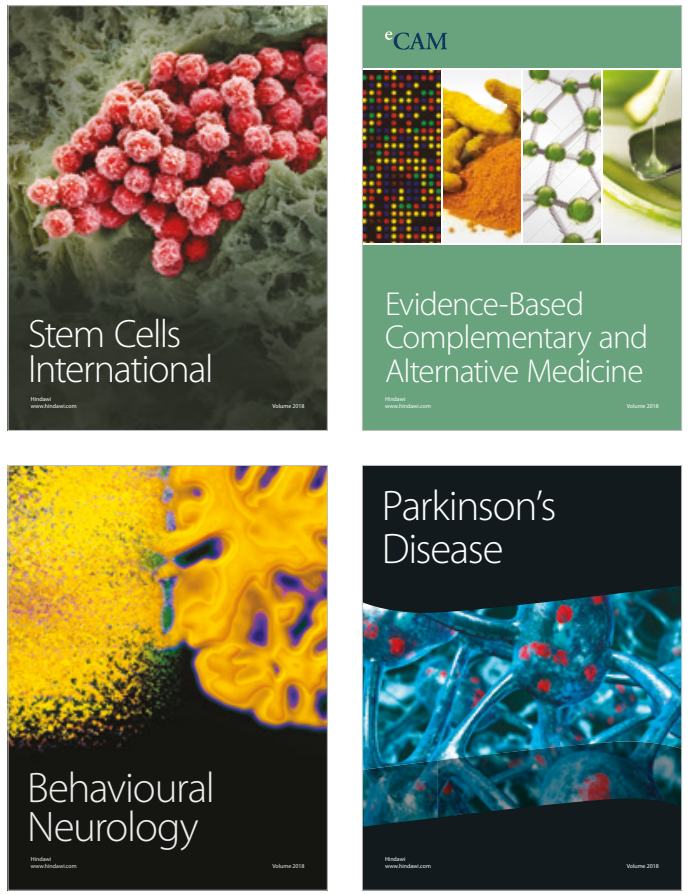

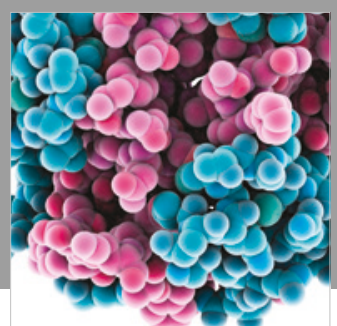

ournal of

Diabetes Research

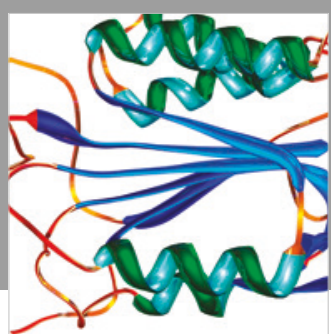

Disease Markers
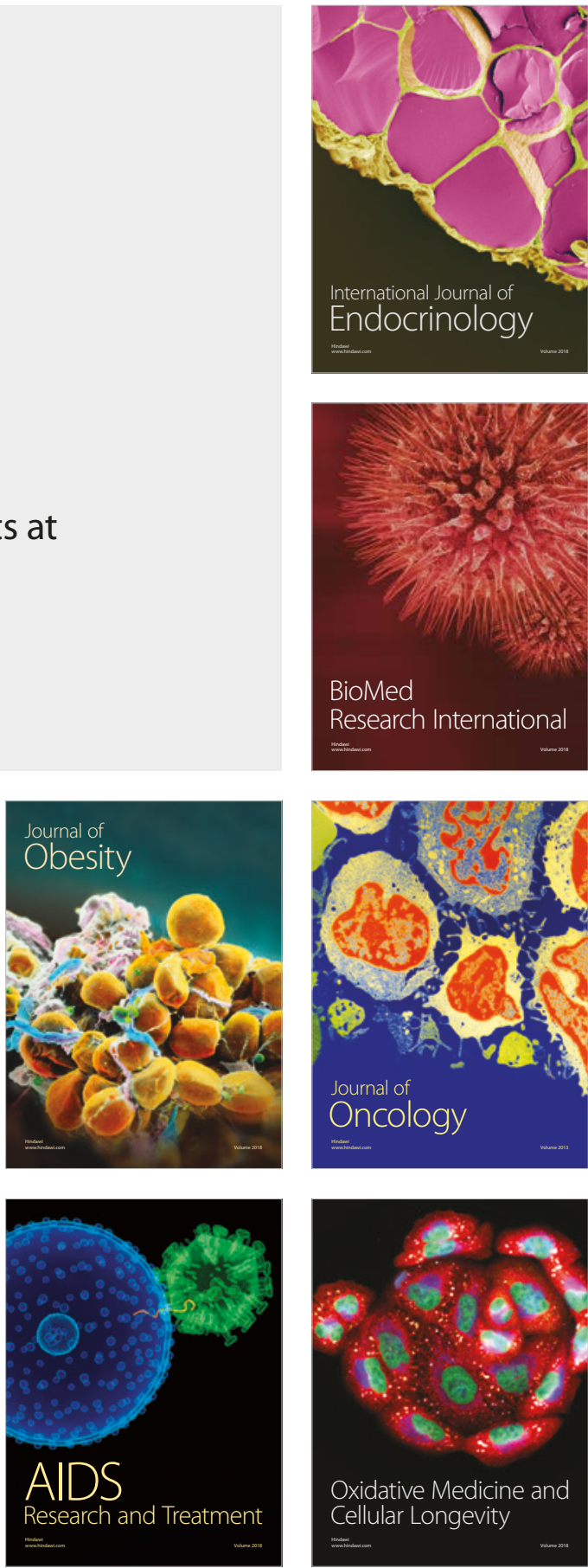